\title{
TRES, TRES, TRIA: TRÊS MODOS DE OUVIR MÚSICA, TRÊS TIPOS DE TEXTURA MUSICAL, TRÊS MOMENTOS DO LATIM NA MÚSICA.
}

\author{
Myrna Bier Appel
}

\begin{abstract}
RESUMO: Une vue panoramique de la présence de la langue latine dans la musique, depuis le chant grégorien jusqu'aux compositions savantes et populaires contemporaines permet de percevoir l'amplitude, l'actualité et la perennité de ce lien, ainsi que la coexistence du latin avec des langues modernes, néolatines ou non, dans un même texte musical. Sont présentés les préceptes d'Aaron Copland concernant l'écoute et la reconnaissance de différents genres et textures musicaux, en vue jouissance subjective/ objective de la musique.
\end{abstract}

PALAVRAS-CHAVE: latim, música, homofonia, monodia, polifonia

\begin{abstract}
"Estudar a transição do canto monódico para o canto polifônico e a evolução deste a partir do início do segundo milênio da era cristã, é acompanhar a revolução mais fascinante sofrida pela música ocidental em toda a sua história; significa ver surgirem nesta arte dimensões inteiramente novas e de uma importância tal que constituem os fundamentos da composição até os nossos dias."
\end{abstract}

Bruno Kiefer

“...do ponto de vista do escritor, a extrema concisão e o potencial de significação da língua latina são ambos um desafio e uma enorme vantagem, especialmente quando se trata de um assunto altamente emocional. Enfim, e não menos importante, o Latim, com sua estrutura fortemente "óssea", canta magnificamente."

Herman Portocarero

\section{TRÊS MODOS DE OUVIR MÚSICA ${ }^{1}$}

Aaron Copland, compositor norte-amnericano, num despretensioso mas muito útil livro destinado a leigos, estabelece três planos de audição de música. O plano sensível, o mais simples, consiste em "entregar-se totalmente ao prazer do som", sem pensar, deixando-se apenas embalar, ou fugindo para um mundo irreal e ideal. É um tipo de fruição musical importante, "mas é apenas uma parte da história". O segundo plano é chamado de expressivo: a rigor, se refere ao significado "musical"da música, uma vez que ele não pode ser explicado por palavras; no entanto, seria possível relacioná-lo com a percepção da qualidade expressiva da música, com referência a estados de espírito, mundo emotivo, sentimentos - serenidade, exaltação, tristeza, vitória, fúria, delícia, etc. O plano puramente musical, o terceiro, é o que exige o desenvolvimento de um tipo especial de percepção, uma conquista à qual se pode chegar através do conhecimento de certos elementos indispensáveis: melodia, ritmo, harmonia, colorido tonal, princípios da forma musical.

Conclui Copland: “...o ouvinte ideal está ao mesmo tempo dentro e fora da música, julgando-a e desfrutando dela (...). Uma atitude subjetivo-objetiva está implícita na criação e na apreciação da música” (COPLAND, 1974, p. 22 a 27).

Myrna Bier Appel, Professora de língua e literatura latinas, é coordenadora, no Instituto de Letras da Ufrgs, do Coral de Letras, que tem como regente, Ignacio Antonio Neis.

${ }^{1}$ Este texto resultou do minicurso ministrado na 51 ${ }^{\mathrm{a}}$ Reunião Anual da SBPC, na PUC/RS, em Porto Alegre (13 a 16 de julho de 1999) e de uma palestra proferida para o setor UNILÍNGUAS da UNISINOS, em São Leopoldo (22 de agosto de 1999). Em ambas as ocasiões, a audição das músicas relacionadas após a Bibliografia, os comentários feitos, a ato de cantar em conjunto o cânone e a projeção de lâminas com reproduções de partituras renascentistas forneceram uma informação mais exata e rica, impossibilitada pelo texto escrito.

Organon, Porto Alegre, no 27, julho-dezembro, 1999, p. 221 - 232 
A explanação do compositor, simples e clara, contém afirmações, como as citadas acima, que podem ser aplicadas também às outras artes. Ao nos defrontarmos com uma obra literária, uma pintura, uma escultura, um filme, seja qual for a linguagem artística em questão, podemos, também, enriquecer e aprofundar nossa fruição estética se nos munirmos de conhecimentos teóricos que, aliados à nossa intuição e sensibilidade, lancem uma luz reveladora sobre o objeto apreciado.

\section{TRÊS TIPOS DE TEXTURA MUSICAL}

Examinar a convivência, a parceria e a cumplicidade mantidas ao longo de quase dois milênios pela música e pelo latim - aqui emparelhados, ali tentando afastar-se, para logo adiante encontrarem-se fortemente unidos - é um exercício fascinante e cheio de surpresas. Mas exige, também, o conhecimento de alguns fundamentos da música e, naturalmente, a possibilidade de ouvir, escutar, e entender os exemplos musicais.

É ainda Copland quem nos fornece explicações acessíveis sobre os três tipos de textura musical: monofônica consiste em uma linha melódica desacompanhada; originária do oriente, passa à Grécia e daí ao Ocidente, que terá no canto gregorino seu melhor desenvolvimento; polifônica - caracteriza a música a várias "vozes" (tanto vocais quanto instrumentais) que se movem em planos melódicos separados e independentes, os quais, aos se cruzarem, formam harmonias; iniciada com o contraponto medieval (puntus contra punctum- em que punctus significa nota), atravessa séculos sofrendo modificações e enriquecimentos, continuando a desenvolver-se mesmo após o império da homofonia que lhe sucede cronologicamente, sendo usada também contemporaneamente; homofônica - é composta de uma melodia principal com acompanhamento em acordes e inexiste até o século XVI; é o tipo de música que estamos acostumados a ouvir e a cantar; os primeiros compositores italianos de ópera a criaram (naturalmente aproveitando os desenvolvimentos anteriores das formas musicais), por apresentar ela maior clareza na compreensão do texto e conseqüente transmissão mais direta da emoção dramática, se comparada à música a várias vozes (e letras) que a antecedeu (Id. ib.p.77-83).

Cada uma dessas espécies de música requer um certo tipo de audição e de fruição; a polifônica, sobretudo, pressupõe o conhecimento de alguns elementos da estrutura musical, para ser apreciada de uma maneira mais rica do que a simples audição sensível ou "ingênua". Em todo caso, o fundamental pode-se dizer que seria a educação do ouvido pela audição freqüente de música polifônica: procurar familiarizar-se com o TEMA - melodia inicialmente apresentada por uma "voz"(que pode significar voz propriamente dita, ou instrumento ou linha melódica) - e procurar descobri-lo sempre que ele reaparecer em outra(s) voz(es) ou instrumento(s), no todo ou em parte, idêntico à primeira vez ou com modificações. Este já é um ótimo exercício de audição "horizontal", que procura identificar linhas melódicas autônomas e não apenas blocos sonoros. Neste sentido, cantar e ouvir atentamente um cânone - forma musical breve, cujo modelo mais conhecido talvez seja Frère Jacques, Frère Jacques, dormez-vous? - auxilia a compreensão e apreensão dessa maneira de ouvir. O que ocorre nos cânones é que uma pequena canção pode ser cantada a duas ou mais vozes, deixando-se um intervalo convencionado de alguns compassos entre o início de cada voz; o resultado será uma harmonia entre as várias vozes simultaneamente cantadas. Este princípio da imitação das vozes é o fundamento do procedimento polifônico. Pensando numa atividade lúdica que exemplifique a forma musical unindo-a ao latim, adaptei um cânone do compositor húngaro Zoltán Kodály (1882-1967), apondo-lhe como texto a declinação do pronome relativo qui quae quod. É possível cantá-lo em uníssono (uma só voz) ou a duas, três ou quatro vozes, entrando as vozes sucessivamente, nos números marcados.

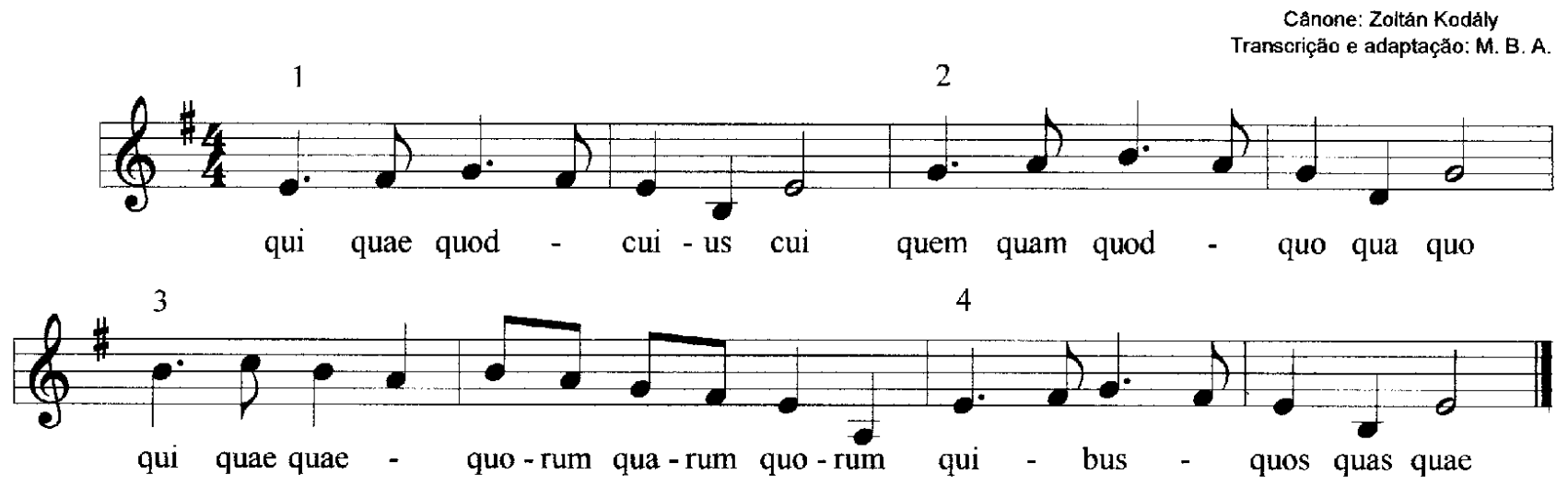

Organon, Porto Alegre, nº 27, julho-dezembro, 1999, p. 221 - 232 


\section{TRÊS MOMENTOS DO LATIM NA MÚSICA}

A história do cristianismo está vinculada à história do Império Romano. Sabemos que, surgindo como seita perseguida, passou a constituir-se, ao longo dos séculos, em religião dominante e, enfim, em herdeira da própria hegemonia do Império. Até 1961, o latim foi a língua oficial da Igreja Católica e os primeiros documentos com notação musical de hinos cristãos o atestam. Foi exatamente em função do desejo e da determinação de unificar a liturgia católica para toda a cristandade que se impôs a necessidade de registrar, através de alguma forma de escrita, as melodias do canto gregoriano, que adquiriu essa denominação por ter sido São Gregório quem, no séc. VI, reuniu num Antifonário as músicas então cantadas nas igrejas, usando uma escrita musical formada por signos originários dos acentos da escrita grega, que forneciam uma vaga idéia do contorno melódico. Serão necessários quase três séculos para que a notação musical permita uma leitura um pouco mais exata, por ação deliberada de Carlos Magno (768-814) que impôs o rito romano a todas as províncias do Ocidente, cercou-se dos homens mais ilustres de sua época, inclusive mestres de música vindos de outros Estados. Num movimento dialético entre crescimento da complexidade dos processos de composição e necessidade de seu registro, em que cada solução encontrada marcava um passo à frente, foi-se desenvolvendo a notação musical, através da experimentação de vários métodos, até chegar-se à concepção de uma linha horizontal, precedida de uma clavis (a "chave"da música), letra que indicava a nota que seria inscrita sobre a linha e que servia de baliza para os movimentos ascendentes ou descendentes da música. Estava criado, então, o processo que daria origem ao pentagrama atual - a pauta de cinco linhas - precedido da clave da tonalidade. Atribui-se a Guido d'Arezzo, na primeira metade do século XI, o uso da pauta de quatro linhas, um desenvolvimento fundamental. As notas tinham então um formato quadrado, decorrente do tipo de pena usado para escrevê-las. Como, quando e por quê o ritmo passa a ser também registrado é uma história complementar, resultante da complexidade crescente das composições (BECK, p.24-61).

O primeiro momento do registro musical foi, portanto, o da música sacra - o cantochão (de cantus planus, denominação descritiva do canto que virá a chamar-se "gregoriano") - que fazia ondular melodicamente o texto latino das orações, dos salmos e outros textos da liturgia católica romana. Ouvir um Pater noster ou uma Ave Maria gregorianos ilustra esta parceria entre música e latim.

A propósito, o texto do Pater noster, presta-se bem à ilustração do estudo dos pronomes possessivos em latim, de sua concordância com os substantivos aos quais estão ligados e da relação entre declinações, casos e desinências. Também a formação da voz passiva no latim, as transformações na sua passagem para o português podem ser aí retomadas. Voltando à música, apreciar o tratamento contemporâneo dado a essa tradicional oração por compositores como o russo Igor Strawisnky e o brasileiro Antônio Vaz, ambos interpretados por corais a quatro vozes mistas, ou a atualíssima interpretação de Caetano Veloso, proporciona um instigante contraste de épocas, estilos, visões de mundo.

Na Idade Média, durante o período gótico, que nos legou admiráveis catedrais, a prática da polifonia deu origem a uma forma musical muito curiosa, o moteto gótico (do francês mot: palavra), pois além de ser polifônico em sentido restrito (várias vozes), era também polirrítmico e até mesmo politextual. Ligada, ainda, à tradição do canto gregoriano, sua vox principalis, o tenor (do latim tenere: segurar, manter) cantava um mot retirado de um canto gregoriano, portanto em latim: Domino, por ex.. A esta melodia, no exemplo dado a seguir, retirado do livro História e significado das formas musicais, do musicólogo e compositor Bruno Kiefer, são superpostas duas outras melodias, em francês da época (séc. XIII), com caráter, texto e ritmo diferentes entre si. Enquanto uma, mais dolente e lenta, canta os males do amor, a superior, alegre e saltitante, louva os encantos da jovem amada. Mesmo quem não lê música pode perceber estas diferenças na letra e na notação musical. A audição deste moteto proporciona uma amostra da sonoridade estranha da música dessa época em que o conceito de consonância e dissonância era diverso daquele que se firmou a partir do séc. XVI e que conforma tradicionalmente nosso ouvido. Ao mesmo tempo, o moteto soa surpreendentemente moderno.

\section{Espaço para partitura}

Este é o segundo momento de convivência do latim e da música; note-se que nele ocorre também o encontro do latim com uma língua vernácula dele originada, o francês, e o encontro da música sacra com a profana. Sem dúvida, a música sacra "pura" desenvolvia-se paralelamente a essa modalidade mista e, sempre que uma arte já bastante fomalizada e intelectualizada se volta para as raízes populares, a síntese resultante representa uma revitalização e um enriquecimento. Com a valiosa contribuição dos trovadores, troveiros, segréis, menestréis da Idade Média, estão lançados todos os fundamentos para o florescimento excepcional da música, tanto sacra quanto profana, durante a Renascença e ao longo dos períodos musicais sucessivos, até chegarmos ao complexo panorama da música atual.

Mas em todas as épocas a convivência "pura" do latim com a música subsistiu na música religiosa e a volta às origens se traduz em reaproveitamentos, ou releituras, para usar um termo em voga, do gregoriano nos mais diversos tipos de composição em todas as épocas. Em Tomás Luis de Victoria, compositor renascentista espanhol, encontramos, v.g., uma

Organon, Porto Alegre, n 27, julho-dezembro, 1999, p. 221 - 232 
Ave Maria que inicia por uma frase gregoriana em uníssono ou solo para depois seguir seu desenvolvimento a quatro vozes com tratamento polifônico, prática corrente na época e mesmo nos séculos seguintes; atualmente, até mesmo grupos de rock, como o grupo El Bosco, inserem palavras ou frases de cantochão em suas composições.

É interessante observar ainda que a coexistência do latim com uma língua vernácula em uma mesma composição se dá tanto com os idiomas neolatinos, como também com o alemão, p.ex.. Uma canção anônima da renascença espanhola, transcrita no Cancioneiro de Upsala (p.115), diz na primeira estrofe:

Yo me soy la morenica,

Yo me soy la morena (com $a$ final tônico)

Soy la sin espina rosa

Que Salomón canta y glosa

Nigra sum sed formosa

Y por mi se cantará.

O verso em itálico, em latim, está inserido com muita naturalidade e até mesmo com rima na estrofe em espanhol.

$\mathrm{O}$ mesmo procedimento de bilingüismo marca um texto de sabor nitidamente popular, em um hino luterano harmonizado na Renascença por Michael Praetorius e retomado no período barroco, por Johann Sebastian Bach em um de seus mais belos corais natalinos; mesclando latim e alemão:

$\begin{array}{ll}\text { In dulci iubilo } & \text { Em doce júbilo } \\ \text { Nun singet und seit froh } & \text { Cantem agora e regozigem-se } \\ \text { Unseres Herzens Wonne } & \text { A alegria do nosso coração } \\ \text { Leit in praesepio } & \text { Está deitada no presépio } \\ \text { Und leuchtet als die Sonne } & \text { E brilha como o sol } \\ \text { Matris in gremio } & \text { No regaço materno } \\ \text { Alpha es } \text { et } O & \text { És alfa e ômega } \\ & \\ \text { Ubi sunt gaudia? } & \text { Onde estão as alegrias? } \\ \text { Nirgend mehr denn da } & \text { Em nenhum outro lugar } \\ \text { Da die Engel singen } & \text { Senão onde os anjos cantam } \\ \text { Nova cantica } & \text { Novos cânticos } \\ \text { Und die Schellen klingen } & \text { E onde os sinos ressoam } \\ \text { In regis curia } & \text { No palácio do rei } \\ \text { Eia, wären wir da } & \text { Ah, estivéssemos nós lá! }\end{array}$

(Do acervo de partituras do Coral de Letras do Instituto de Letras da UFRGS)

Em pleno séc. XX, o compositor alemão Carl Orff, que também desenvolveu um admirável trabalho pedagógico, criando um método de musicalização que leva seu nome, voltou-se para a Antigüidade Clássica e para a Idade Média a fim de buscar textos para duas de suas obras mais conhecidas. Catulli Carmina, como anuncia o título, é uma composição cênica construídas sobre poemas de Catulo, inclusive os sempre lidos e estudados Vivamus, mea Lesbia, atque amemus e Odi et Amo. Já em Carmina Burana, que possui até uma versão cênica em vídeo, embora seja mais freqüentemente executada em forma de concerto, são apresentados poemas em latim medieval (é interessante comparar suas modificações com relação ao latim clássico), francês e alemão arcaicos. Cada uma dessas obras mereceria um estudo à parte, o que já fizemos em outras ocasiões.

Para o terceiro momento da convivência latim-música escolhi uma obra recente. Tem ela a peculiaridade de ser composta sobre poemas em latim, escritos especificamente para a obra, portanto um latim atual, mas ao mesmo tempo clássico em suas características de propriedade, clareza, concisão. Trata-se de um Requiem, isto é, uma Missa de Defuntos que, no entanto, não utiliza o texto tradicional da liturgia cristã. São palavras de Herman Portocarero, libretista de Flamma Flamma - The Fire Requiem, no texto do CD:

"A idéia era escrever uma obra cuja estrutura e propósito seguissem de perto o Requiem Latino, sendo, ao mesmo tempo, mais secular e mágica - preferentemente a religiosa - em seu conteúdo.

Nós decidimos que o Latim era a melhor língua para tal propósito. Primeiro, porque o latim ainda suscita um certo misticismo e, por isso, pareceu-nos naturalmente adequado ao nosso propósito. Segundo, porque ele tem as qualidades paradoxais de ser, ao mesmo tempo, uma língua morta mas, de certa maneira, ainda universal. Os textos latinos transmitiriam sentimentos que iriam totalmente contra os sentimentos religiosos tradicionais dos textos de Requiem existentes. Este contraste seria chocante (...). Enfim, e não menos importante, o Latim, com sua forte estrutura "óssea", canta magnificamente."

(Omiti, para não repetir, o trecho que serve de epígrafe a este texto.)

Afirma o compositor Nicholas Lens que este Requiem do Fogo é um ritual fortemente influenciado pelos poderes mágicos das culturas não-européias. Na composição opõem-se seis cantores clássicos - que simbolizam deuses ou a mais alta consciência do homem - ao coro étnico das vozes búlgaras, que se comprazem em perturbar o tom solene dos deuses, ridicularizando a morte, já que ela ainda não lhes diz respeito. Além disso, mesclam-se instrumentos sinfônicos, com eletrônicos e étnicos: esta mistura representa o amálgama da "rica, antiga, mas gasta cultura européia com o frescor 
vigoroso e muitas vezes surpreendente das culturas primitivas". Ainda citando Lens: "Flamma Flamma enfatiza as emoções puramente humanas diante da transição cósmica, respeitosamente, porque independente de qualquer filosofia conhecida."

Nas catorze faixas que o compõem, o CD apresenta sucessivamente a cena do velório - Hic iacet corpus/animae carcer (Aqui jaz o corpo, cárcere da alma), as personagens presentes - vizinhas, carpideiras, órfãos, viúvas, prostitutas - e as diversas perdas que sofremos no percurso da vida: a morte do pai, da mãe, do irmão, do amigo, do inimigo, da pessoa amada; a consagração do fogo, a invocação a ele, a oferenda do corpo morto às chamas, e a imolação do cordeiro conduzem ao final, Ardeat ignis, em que uma oração ao fogo roga-lhe que libere a alma.

Assim, se o tema da obra é a transmutação cósmica pela morte, o fogo constitui o elemento e a metáfora central:

fogo é o sol que vivifica mas também acelera a putrefação;

fogo é a chama do amor, labareda que arde mais que o fogo;

fogo é o sangue que jorra do cordeiro sacrificado;

fogo é a chama da pira funerária que, queimando o corpo, libera a alma.

O texto sacro, mas não cristão, evoca leituras da antigüidade clássica; trechos e episódios da Eneida nos vêm à mente, assim como textos de Cícero, Sêneca et alii.

Alguns poemas servem para ilustrar o teor do texto, mas é claro que só a audição da obra pode oferecer sua real dimensão. A morte do pai é evocada em :

TEGITE SPECULA
Tegite specula
Pater mortuus est
Odimus et amamus eum
Cuius sanguinem et nomen
Insanabile gerimus
Specula tegimus
Quia vultus pater
Persona iam mortis nostrae fit
Sicut cicatrix vitae quam
Insanabile gerimus

\author{
Cubram os espelhos \\ Cubram os espelhos \\ O pai morreu \\ Odiamos e amamos aquele \\ Cujo sangue e nome \\ Carregamos irremediavelmente \\ Cobrimos os espelhos \\ Porque a face do pai \\ Já se torna a máscara da nossa morte \\ Como uma cicatriz da vida \\ Que carregamos irremediavelmente
}

A virulência do ódio ao inimigo se revela em:

$\begin{array}{ll}\text { CORPUS INIMICI } & \text { O corpo do inimigo } \\ \text { Corpus inimici } & \text { O corpo do inimigo } \\ \text { Conspuo } & \text { Conspurco } \\ \text { Odium flamma erat } & \text { O ódio era uma chama } \\ \text { Vita ipsa } & \text { Seja a própria vida } \\ \text { Sit ultio mea } & \text { Minha vingança }\end{array}$

A perda da amada inspira o poema mais lírico:

$\begin{array}{ll}\text { DELICIAE MEAE } & \text { Meu amor } \\ \text { Deliciae meae } & \text { Meu amor } \\ \text { Venustas tua } & \text { Tua beleza } \\ \text { Ipsi morti superest } & \text { Sobrevive à própria morte } \\ \text { Ultimum lavabo } & \text { Pela última vez lavarei } \\ \text { Corpus nudum tuum } & \text { Teu corpo nu } \\ \text { Lacrimis meis } & \text { Com minhas lágrimas } \\ \text { Pyra non altius } & \text { A pira não pode } \\ \text { Amoris mei igne } & \text { Arder mais alto } \\ \text { Ardere potest } & \text { do que o fogo do meu amor } \\ \text { Invideo et odi } & \text { Invejo e odeio } \\ \text { Servos funebres quibus } & \text { Os servos fúnebres aos quais } \\ \text { Te tangere licet } & \text { É lícito tocar-te } \\ & \text { Depois de mim } \\ \text { Post me } & \text { Nenhum amante } \\ \text { Procus nullus } & \text { Senão a morte } \\ \text { Nisi mors } & \text { Te possuirá } \\ \text { Te possidet } & \end{array}$


A primeira inscrição em língua latina data de ca. 600 a.C.. Portanto, no séc. I a.C., quando poetas, oradores e prosadores já tinham burilado o latim a ponto de torná-lo um idioma fértil e apto para expressar todos os tipos de pensamento e toda a gama dos sentimentos humanos, seis séculos eram já transcorridos.

Hoje, no limiar do terceiro milênio, a aliança entre latim e música confirma que os romanos nos legaram uma cultura e uma língua que são um verdadeiro monumentum aere perenius, ou seja, um monumento mais perene que o bronze.

\section{BIBLIOGRAFIA}

BECK, Jean. La musique des troubadours. Evreux: Hérrissey, s.d.

BRENET, Michel. Diccionario de la música. Barcelona, Joaquim Gil, 1946.

CANCIONEIRO de Upsala. Introdução e notas de Rafael Metjana. México, Fondo de Cultura Económica, s.d.

CARMINA Burana. Programa 1991._Conjunto de Câmara de Porto Alegre. Coord.Marlene Goidanich. (fascículo)

CARMINA Burana. Trad. introd. e notas de Maurice von Woensel. São Paulo, Ars Poetica, 1994.

COMBARIEU, J. Histoire de la musique: des origines à la fin du XVIe siècle.Paris, Armand Colin, 1950. v.1.

COPLAND, Aaron. Como ouvir (e entender) música. Rio de Janeiro, Artenova, 1974.

DICCIONARIO de la música Labor. Barcelona, Labor, 1954.

DICIONÁRIO Grove de música. Rio de Janeiro, Zahar, 1994.

ENCYCLOPÉDIE de la musique. Paris, Fasquelle, 1961.

GROVE'S dictionary of music and musicians. London, Macmillan, 1954.

HARNONCOURT, Nikolaus. O diálogo musical: Monteverdi, Bach e Mozart. Rio de Janeiro, Jorge Zahar, 1993.

KIEFER, Bruno. História e significado das formas musicais. Porto Alegre, Movimento, 1981.

LA MUSIQUE: des origines à nos jours. Paris, Larousse, 1946.

LEITE, J.F.M. \& JORDÃO, A. J. Dicionário latino vernáculo: etimologia, literatura, história, mitologia,_geografia. Rio de

Janeiro, Henrique Velho, 1944.

ROLDÁN, Waldemar Axel. Cultura musical II. 17.ed. Buenos Aires, El Ateneo, 1995.

SAID ALI, M. Meios de expressão e alterações semânticas. 2.ed.rev. Rio de Janeiro, Simões, 1951.

\section{ANEXOS}

\section{RELAÇÃO DAS MÚSICAS CANTADAS/OUVIDAS}

\begin{tabular}{|c|c|c|}
\hline Título & Autor/espécie/século & Intérpretes \\
\hline Ave Maria & Canto gregoriano (I.M.) & Coro Mediolanensis (Itália) \\
\hline Ave Maria & Tomás Luis de Victória (XVI) & Niños Cantores de Córdoba \\
\hline Pater noster & Canto gregoriano (I.M.) & Monges Abadia Solesmes \\
\hline Pater noster & Igor Strawinsky $(\mathrm{XX})$ & Kammerchor Lienz \\
\hline Pater noster & Antônio Vaz (XX) & Coral Unisinos, Reg. J.P. Sefrin \\
\hline Gutta cavat lapidem & Antônio Salieri (XVIII) & Alunos da Escola F. Wilhelm \\
\hline Gaudeamus igitur & (desconhecido) & (sem registro) \\
\hline $\begin{array}{l}\text { Flamma Flamma: } \\
\text { III. Tegite specula } \\
\text { VIII. Corpus inimici } \\
\text { IX. Deliciae meae }\end{array}$ & $\begin{array}{l}\text { NicholasLens/Herman } \\
\text { (XX) }\end{array}$ & (ver referência no CD) \\
\hline
\end{tabular}

Organon, Porto Alegre, no 27, julho-dezembro, 1999, p. 221 - 232 


\begin{tabular}{|l|l|l|}
\hline $\begin{array}{l}\text { Catulli Carmina: } \\
\text { Odi et amo } \\
\text { Vivamus mea Lesbia }\end{array}$ & Carl Orff (XX)/ Catulo (I a . C.) & The Vienna Chamber Choir \\
\hline Pingos d'água & Henrique de Curitiba (XX) & Coral Unisinos, Reg.J.P.Boéssio \\
\hline
\end{tabular}

